\title{
Prevalence and Socio-Demographic Correlates of Substance Use Among Patients Attending the drug Unit of the University of Port Harcourt Teaching Hospital
}

\author{
Nkporbu $\mathrm{AK}^{1 *}$, Oti, IK ${ }^{2}$ and Ugbomah $\mathrm{L}^{1}$ \\ ${ }^{1}$ Drug Unit, University of Port Harcourt Teaching Hospital, Nigeria \\ ${ }^{2}$ Physiotherapy Department, University of Port Harcourt Teaching Hospital, Nigeria
}

*Corresponding author: Nkporbu AK, (MB, BS, MSc, MPH (UPH), FWACP, ICAP, Cert. LMIH (Washington)) Drug Unit, University of

Port Harcourt Teaching Hospital, Nigeria

\section{ARTICLE INFO}

Received: 幽 September 20, 2021

Published: 杫 September 27, 2021

Citation: Nkporbu AK, Oti, IK, Ugbomah L. Prevalence and Socio-Demographic Correlates of Substance Use Among Patients Attending the drug Unit of the University of Port Harcourt Teaching Hospital. Biomed J Sci \& Tech Res 39(1)-2021. BJSTR. MS.ID.006241.

Keyword: Prevalence; Socio-Demographic Correlates; Substance Use; Drug Unit; UPTH

\section{ABSTRACT}

Background: Substance use in different parts of the world seems to be on the increase and has continued to pose a threat to the health, social and economic fabric of families, communities and nations.

Aim of the Study: This study investigated the prevalence and socio-demographic characteristics of substance use among patients on drug treatment at University of Port Harcourt Teaching Hospital.

Methods: The NENDU data of attendees of the Drug Unit of the University of Port Harcourt Teaching Hospital from January 2018 to February 2020 were studied following ethical clearance using a descriptive retrospective study design. Analysis of data was done using the Statistical Package for Social Sciences (SPSS) software version 20.

Results: A total of 104 patients were registered for treatment at the facility within the period studied. Results revealed that $42.3 \%$ (43 males, 1 female) used cannabis, alcohol was $13.5 \%$ (14 males, no female), tobacco $11.5 \%$ (12 males, no female), opioids $9.62 \%$ ( 8 males, 2 females), tramadol 7.69\% (6 males, 2 females), cocaine $4.81 \%$ (5 males, no female), codeine $3.85 \%$ ( 4 males, no female) , pentazocine $2.88 \%$ ( 2 males, 1 female), cracked cocaine $1.98 \%$ (2males, no female), while $0.96 \%$ ( 2 males, no female) used sedative hypnotics and hallucinogens. Majority of the subjects were males 98 (94.2\%), singles 93 (89.4\%), and had tertiary education 73 (75.0\%).

Conclusion: The study concluded that there is a substantial prevalence of substance use, and that it is mostly among single males in tertiary institutions.

\section{Introduction}

According to the World Health Organization [1], substance use refers to the use of any psychoactive substances or drugs, which include licit and illicit drugs, other than which are medically indicated. The United Nations Organizations on Drug Council [2] stated that substance use is a major public health problem all over the world. In 2011, it was estimated that 167 to 315 million people aged 15 to 64 years globally had used an illicit substance in the preceding year [3]. The estimated global burden of alcohol and illicit drugs use is 5.4\% while tobacco is 3.7\% [4]. Psychoactive substance use poses a threat to the health, social and economic fabric of families, communities and nations [5]. Drug dependence is a growing public health problem and consequences of drug 
dependence cost the community heavily [6]. This habit not only affects health, education and occupational career, but it also incurs a huge financial and social burden on the society.

A national survey of substance use conducted among 10,609 Nigerians aged 15-64 years in the six geopolitical zones of the country recorded a lifetime prevalence of $39 \%$ for alcohol, $6.6 \%$ for cannabis and $12.2 \%$ for cigarettes [7]. In Nigeria, the most common types of used substances include stimulants and amphetamines such as caffeine, tobacco, nicotine, ephedrine; hallucinogens such as marijuana and narcotics such as heroine and codeine. Others include alcohol and sedatives [8]. These substances are largely used due to the belief that they relieve stress and anxiety, and some of them induce sleep, ease tension, cause relaxation or help users to forget their problems. The consequences of their abuse could result in physical dependence [8].

The United Nations Organizations on Drug Council [2] submitted that prevalence of any drug use in Nigeria is estimated at 14.4 per cent or 14.3 million people aged between 15 and 64 years; a situation which implies that the extent of drug use in Nigeria is comparatively high when compared with the 2016 global annual prevalence of any drug use of 5.6 per cent among the adult population. Accordingly, one in seven persons aged 15-64 years in Nigeria had used a drug (other than tobacco and alcohol) in the past year [2]. The social consequences of drug use are also evident in Nigeria. Some of which include disruption in family lives, loss in productivity and legal problems as a consequence of drug use in their communities. Also, some individuals in the general population had experienced negative consequences due to other peoples' drug use in their families, workplace and communities [5].

Despite the highly reported consequences of substance use, in different parts of the world including Nigeria, a good number of individuals' reports being addicted to specific drugs and presents at healthcare facilities for medical assistance [4]. In fact, in University of Port Harcourt Teaching Hospital, Rivers State Nigeria, some people who have willingly presented themselves for clinical counseling are currently on drug rehabilitation. Nonetheless, there is dearth of evidence on the prevalence of substance use disorders in Nigerian communities, a situation which justifies the need for this study on the prevalence and socio-demographic correlates of substance use disorders among individuals on drug rehabilitation in University of Port Harcourt Teaching Hospital.

\section{Methodology (Materials and Method)}

\section{Study Design}

Descriptive retrospective design was used in this study.

\section{Study Subjects}

The target population consisted of all adult males and females on drug rehabilitation in University of Port Harcourt Teaching. Only subjects who been on drug rehabilitation for a minimum period of six months and were willing to participate were included in the study. The study was conducted from January 2018 to February 2020. A sample size of 104 subjects was selected using the purposive sampling technique. Sample size determination was done using sample size determination formula by Cochran as shown below:

$$
\begin{aligned}
& N=Z^{2} P(1-P) / d^{2} \\
& \text { Where } N=\text { Sample size } \\
& P=\text { Prevalence of drug use }=(6.6 \%)=[0.066][7] . \\
& d=\text { Sampling error that can be tolerated }(0.05) \\
& Z=\text { Level of Significance } \\
& N=1.9620 .066(1-0.066) / 0.0025 \\
& =0.2368115904(0.856) / 0.0025 \\
& =94.725 \\
& =94.7
\end{aligned}
$$

$10 \%$ non-respondent $=94.7$ of $10 \%=9.47$

$\mathrm{N}=94.7+9.47=104.17$

\section{Data Collection}

The Nigerian Epidemiological Network on Drug use for drug patients who attended UPTH treatment facility from January 2018 to February 2020 were retrieved and used in the study following ethical clearance.

\section{Data Analysis}

Analysis of data was done using the Statistical Package for Social Sciences (SPSS) software version 20.

\section{Results}

Table 1 shows that majority of the respondents were males, $94.2 \%$, had tertiary education, $75.0 \%$ and were single, $89.4 \%$.

Table 2 shows that sex of individuals influences their substance use behaviour, as majority of the respondents that uses substances/ drugs were males $(\mathrm{P}<0.05)$.

Table 3 shows that marital status of individuals influences their substance use behaviour, as majority of the respondents that uses substances/drugs were singles $(\mathrm{P}<0.05)$. 
Table 4 shows that educational status of individuals influence their substance use behaviour, as majority of the respondents that uses substances/drugs had tertiary education $(\mathrm{P}<0.05)$.

Table 5 shows the prevalence of substance use disorders among individuals on drug rehabilitation in University of Port
Harcourt Teaching Hospital. Out of the 104 respondents, 42.3\% use cannabis, $13.5 \%$ consume alcohol, $11.5 \%$ use tobacco, $9.62 \%$ use opioids, $7.69 \%$ use Tramadol, $4.81 \%$ use cocaine, $3.85 \%$ use codeine, $2.88 \%$ use Pentazocine, $1.98 \%$ use cracked cocaine, while $0.96 \%$ use sedative hypnotics and hallucinogens.

Table 1: Socio-Demographic Characteristics of the Subjects $(n=104)$.

\begin{tabular}{|c|c|c|c|}
\hline Variables & Categories & Frequency & Percentage \%) \\
\hline \multirow{2}{*}{ Sex } & Male & 98 & 94.2 \\
\cline { 2 - 4 } & Female & 6 & 5.8 \\
\hline \multirow{2}{*}{ Education } & Secondary & 26 & 25 \\
\cline { 2 - 4 } & Tertiary & 78 & 75 \\
\cline { 2 - 4 } & Single & 93 & 89.4 \\
\cline { 2 - 4 } & Married & 9 & 8.7 \\
\cline { 2 - 4 } & Divorced/Separated & 2 & 1.92 \\
\cline { 2 - 4 } & Widowed & 1 & 0.96 \\
\hline
\end{tabular}

Table 2: Sex of Subjects and Use of Substances among Individuals on Drug Rehabilitation in University of Port Harcourt Teaching Hospital ( $\mathrm{n}=104)$.

\begin{tabular}{|c|c|c|c|}
\hline \multirow{2}{*}{ S/N } & Substance of use/misuse & Male & \multicolumn{2}{|c|}{ Fex } \\
\cline { 3 - 4 } & & 43 & 1 \\
\hline 1 & Cannabis & 8 & 2 \\
\hline 2 & Opioids & 5 & - \\
\hline 3 & Cocaine & 2 & - \\
\hline 4 & Cracked cocaine & 2 & 2 \\
\hline 5 & Pentazocine & 6 & - \\
\hline 6 & Tramadol & 14 & - \\
\hline 7 & Alcohol & 4 & - \\
\hline 8 & Codeine & 12 & \\
\hline 10 & Tobacco & 1 & \\
\hline 11 & Sedative hypnotics & & - \\
\hline
\end{tabular}

Table 3: Marital Status of Subjects and Use of Substances among Individuals on Drug Rehabilitation in University of Port Harcourt Teaching Hospital ( $\mathrm{n}=104)$.

\begin{tabular}{|c|c|c|c|c|c|}
\hline \multirow{2}{*}{ S/N } & \multirow{2}{*}{$\begin{array}{c}\text { Substance of use } \\
\text { misuse }\end{array}$} & \multicolumn{4}{|c|}{ Marital Status } \\
\cline { 3 - 5 } & Cannabis & Single & Married & Divorced & Widowed \\
\hline 1 & Opioids & 44 & - & - & - \\
\hline 2 & Cocaine & 5 & - & - & - \\
\hline 3 & Cracked cocaine & 2 & - & - & - \\
\hline 4 & Pentazocine & 2 & - & - & - \\
\hline 5 & Tramadol & 8 & - & 2 & - \\
\hline 6 & Alcohol & 12 & - & - & - \\
\hline 7 & Codeine & 4 & 1 & - & - \\
\hline 8 & Tobacco & 11 & - & - & - \\
\hline 9 & Sedative hypnotics & 1 & - & - & - \\
\hline 10 & Hallucinogen & 1 & & - \\
\hline
\end{tabular}


Table 4: Educational Status of Subjects and Use of Substances among Individuals on Drug Rehabilitation in University of Port Harcourt Teaching Hospital $(n=104)$.

\begin{tabular}{|c|c|c|c|}
\hline \multirow{2}{*}{ S/N } & Substance of use/misuse & Secondary & \multicolumn{2}{|c|}{ Education } \\
\cline { 3 - 4 } & & 6 & 38 \\
\hline 1 & Cannabis & 1 & 9 \\
\hline 2 & Opioids & - & 5 \\
\hline 3 & Cocaine & - & 2 \\
\hline 4 & Cracked cocaine & 1 & 7 \\
\hline 5 & Pentazocine & 1 & 10 \\
\hline 6 & Tramadol & 4 \\
\hline 10 & Alcohol & 1 & 3 \\
\hline 11 & Codeine & 2 & 10 \\
\hline
\end{tabular}

Table 5: Prevalence of Substance Use Disorders among Individuals on drug Rehabilitation in University of Port Harcourt Teaching Hospital (N=104).

\begin{tabular}{|c|c|c|c|c|}
\hline S/N & Substance of Use & Frequency & Percentage (\%) & Rank \\
\hline 1 & Cannabis & 44 & 42.3 & $1^{\text {st }}$ \\
\hline 2 & Opioids & 10 & 9.62 & $4^{\text {th }}$ \\
\hline 3 & Cocaine & 5 & 4.81 & $6^{\text {th }}$ \\
\hline 4 & Cracked cocaine & 2 & 1.92 & $9^{\text {th }}$ \\
\hline 5 & Pentazocine & 3 & 2.88 & $8^{\text {th }}$ \\
\hline 6 & Tramadol & 8 & 7.69 & $5^{\text {th }}$ \\
\hline 7 & Alcohol & 14 & 13.5 & $2^{\text {nd }}$ \\
\hline 8 & Codeine & 4 & 3.85 & $7^{\text {th }}$ \\
\hline 9 & Tobacco & 12 & 1.5 & $3^{\text {rd }}$ \\
\hline 10 & Sedative hypnotics & 1 & 0.96 & $10^{\text {th }}$ \\
\hline 11 & Hallucinogen & 1 & 0.96 & $10^{\text {th }}$ \\
\hline
\end{tabular}

\section{Discussion}

The study findings revealed an increasing prevalence of substance use. Out of the 104 respondents, $42.3 \%$ used cannabis, $13.5 \%$ consumed alcohol, $11.5 \%$ used tobacco, $9.62 \%$ used opioids, 7.69\% used Tramadol, $4.81 \%$ used cocaine, 3.85\% used codeine, $2.88 \%$ used Pentazocine, $1.98 \%$ used cracked cocaine, while $0.96 \%$ used sedative hypnotics and hallucinogens. These results agree with the findings of Oshodin [8], Adamson et al. [7], Morello et al. [9] and Jegede et al. [10]. Generally, cannabis, alcohol and tobacco appear cheaper and more readily available to the average Nigerian drug user than the other substances, a situation that explains why they are more prevalent. This may not be the case in other subSaharan African countries and the rest of the world.

It was also discovered that sex, marital and educational status of individuals influence their substance use behaviour, as majority of the subjects were males 98 (94.2\%), singles 93 (89.4\%), and had tertiary education 73 (75.0\%). These results are in consonance with the assertion of Okpataku [11]. The married ones were less likely to use drugs etc. A possible reason for this socio-demographic correlate could be that males are usually more adventurous than the female folks! Although this assertion may be considered true to a large extent, it is actually not absolute as Adolfo et al. [12] in their study reported otherwise. They found out that drug use was more prevalent among women. The possible reason for this difference could be that of setting and culture. Whereas this present study was conducted in Port Harcourt, South-South Nigeria, Adolfo et al. [12] conducted theirs in Spain, Europe. On the other hand, drug use being more prevalent among singles could be due to the fact that they generally have more freedom and less restriction in the adventures of life more than the married, divorced and widowed etc. Also, the fact that most of the drug users had tertiary education explains the fact that growth, peer pressure or exposure to a higher degree of thinking/learning could actually predispose one to certain habits 
such as drug abuse etc. This may actually not be absolute globally as some other studies have identified substantial drug use among high school students, dropouts and street hustlers [2].

\section{Conclusion}

In conclusion, there is a high prevalence of drug use in the society; cannabis and alcohol are the most substances of use/ misuse. There is a significant relationship between socialdemographic characteristics of individuals and their potential to use substances as sex, marital and educational status of individuals influences the extent to which they use drugs and related items. A substantial proportion of the subjects that use substances/drugs were males' singles and had tertiary education.

\section{Recommendations}

1. Public healthcare practitioners should organize sensitization programmed in communities aimed at educating members of the society on the harmful consequences of substance abuse and the need to develop positive health related behaviour.

2. Groups helpful in discouraging substance use and misuse should be established in communities

3. Government should adequately enforce laws prohibiting illegal substance use in the society.

4. Focused management of substance use disorders in healthcare facilities is also recommended.

5. Individuals on drug rehabilitation should be provided with adequate social and related support.

\section{Conflict of Interest}

No conflict of interest with any institution/organization.

\section{ISSN: 2574-1241}

DOI: 10.26717/BJSTR.2021.39.006241

Nkporbu AK. Biomed J Sci \& Tech Res

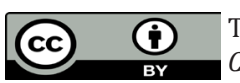

This work is licensed under Creative Commons Attribution 4.0 License

Submission Link: https://biomedres.us/submit-manuscript.php

\section{References}

1. (2020) World Health Organization. Guide to drug use epidemiology.

2. (2005) United Nations Organizations on Drug Council (UNODC). World Health Organization Expert Committee on Dependence Producing Drugs. Fourteenth Report Urban Adolescents", Child Development 61: 2032-2046

3. (2013) United Nations Organizations on Drug Council (UNODC). World Drug Report 2013.

4. (2010) World Health Organization. WHO Atlas on substance use, resources for the prevention and treatment of substance use disorders, World Health Organization, Geneva, Switzerland.

5. Gupta S, Sarpal SS, Kumar D, Kaur T, Arora S (2013) Prevalence, pattern and familial effects of substance use among the male college students: A North Indian Study. J Clin Diagn Res 7(8): 1632-1636.

6. Ningombam S, Hutin Y, Murhekar MV (2011) Prevalence and pattern of substance use among the higher secondary school students of Imphal, Manipur, India. Natl Med J India 24(1): 11-15.

7. Adamson TA, Ogunlesi AO, Morakinyo O, Akinhanmi AO, Onifade PO, et al. (2015) Descriptive national survey of substance use in Nigeria. J Addict Res Ther 6: 234.

8. Oshodin OG (2004) Are you not also guilty of drug abuse? Health education and cultural strategies to the rescue. Inaugural lecture series 72. Benin: University of Benin Press 10.

9. Morello P, Perez A, Penal L, Braun SN, Koilath C, et al. (2017) Risk factors associated with tobacco, alcohol and drug use among adolescents attending secondary school in three cities from Argentina. Arch Argent Pediatr 115(2): 155-158.

10. Jegede O, Ojo O, Saad A, Kodjo K, Virk I, et al. (2018) Tobacco and Substance Use among Psychiatric Inpatients in a Community Hospital: Cessation Counseling, Correlates, and Patterns of Use. J Addict.

11. Okpataku CI (2016) Socio-demographic correlates of substance use among long distance commercial vehicle drivers. J Med Trop 18: 6-11.

12. Adolfo S, Otero JJG, Caamano-Isorna F (2000) Sociodemographic factors related to self-medication in Spain. European Journal of Epidemiology 16(1): 19-26.

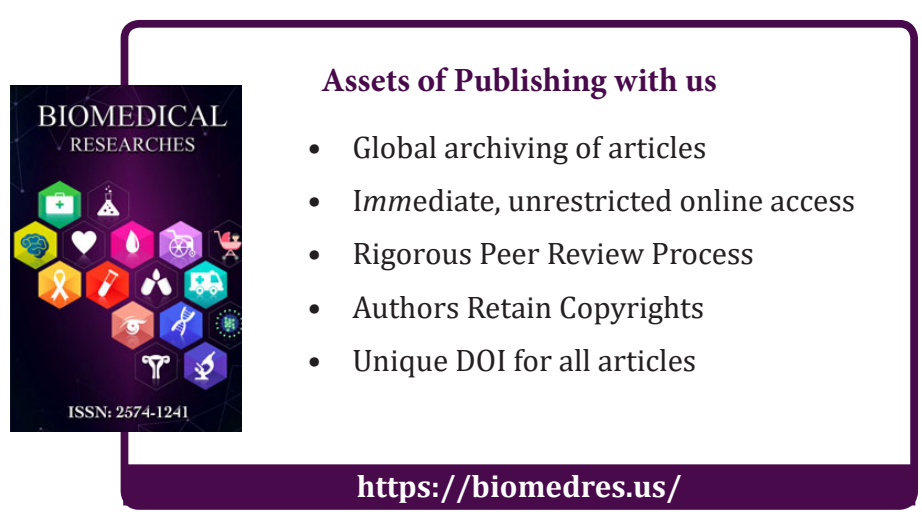

